\title{
Nestin Is Not Essential for Development of the CNS But Required for Dispersion of Acetylcholine Receptor Clusters at the Area of Neuromuscular Junctions
}

\author{
Paria Mohseni, ${ }^{1,2 *}$ Hoon-Ki Sung, ${ }^{1 *}$ Amanda J. Murphy, ${ }^{3}$ Christine L. Laliberte, ${ }^{4}$ Hanna-Mari Pallari, ${ }^{5}$ \\ Mark Henkelman, ${ }^{4}$ John Georgiou, ${ }^{1}$ Gang Xie, ${ }^{1}$ Susan E. Quaggin, ${ }^{1}$ Paul S. Thorner, ${ }^{3,6}$ John E. Eriksson, ${ }^{5}$ \\ and Andras Nagy ${ }^{1,2}$ \\ ${ }^{1}$ Samuel Lunenfeld Research Institute, Mount Sinai Hospital, Toronto, Ontario, M5T 3H7 Canada, ${ }^{2}$ Department of Molecular Genetics, University of \\ Toronto, Toronto, Ontario, M5S 1A8 Canada, ${ }^{3}$ Department of Pediatric Laboratory Medicine, Hospital for Sick Children, Toronto, Ontario, M5G 1X8 \\ Canada, ${ }^{4}$ Mouse Imaging Centre, Department of Medical Biophysics, Hospital for Sick Children, Toronto, Ontario, M5T 3H7 Canada, ${ }^{5}$ Turku Centre of \\ Biotechnology, Åbo Akademi University and University of Turku, Turku, FIN-20521 Finland, and ' $D$ epartment of Laboratory Medicine and Pathobiology, \\ University of Toronto, Toronto, Ontario, M5S 1A8 Canada
}

Nestin is expressed in many different progenitors during development including those of the CNS, heart, skeletal muscle, and kidney. The adult expression is mainly restricted to the subependymal zone and dentate gyrus of the brain, the neuromuscular junction, and renal podocytes. In addition, this intermediate filament protein has served as a marker of neural stem/progenitor cells for close to 20 years. Therefore it is surprising that its function in development and adult physiology is still poorly understood. Here we report that nestin deficiency is compatible with normal development of the CNS. The mutant mice, however, show impaired motor coordination. Furthermore, we found that the number of acetylcholine receptor clusters, the nerve length, and the endplate bandwidth are significantly increased in neuromuscular junction area of nestin-deficient mice. This is similar to the phenotype described for deficiency of cyclindependent kinase 5 (Cdk5), a candidate downstream affecter of nestin. Moreover, we demonstrate that nestin deficiency can rescue maintenance of acetylcholine receptor clusters in the absence of agrin, similar to Cdk5/agrin double knock-outs, suggesting that the observed nestin deficiency phenotype is the consequence of aberrant Cdk5 activity.

\section{Introduction}

Nestin has been extensively used as a marker for neural stem/ progenitor cells both in vitro and in vivo (Lendahl et al., 1990; Doetsch et al., 1997; Mignone et al., 2004). Outside of the developing nervous system, the expression of nestin is detected in muscle precursors (Sejersen and Lendahl, 1993), and cells of the developing heart, testis, and kidney (Kachinsky et al., 1995; Fröjdman et al., 1997; Chen et al., 2006). As cells reach terminal stages of differentiation, nestin is downregulated and replaced by tissue-specific intermediate filaments (IFs) (Kaplan et al., 1990).

\footnotetext{
Received Aug. 20, 2010; revised May 11, 2011; accepted June 1, 2011

Author contributions: P.M., H.-K.S., J.E.E., and A.N. designed research; P.M., H.-K.S., A.J.M., C.L.L., H.-M.P., M.H., J.G., G.X., and P.S.T. performed research; P.M., H.-K.S., A.J.M., C.L.L., G.X., S.E.Q., P.S.T., J.E.E., and A.N. analyzed data; P.M., H.-K.S., A.J.M., M.H., P.S.T., J.E.E., and A.N. wrote the paper.

*P.M. and H.-K.S. contributed equally to this work.

This work was supported in part by the Canadian Stem Cell Network. We thank Dr. Kuo-Fen Lee for sharing unpublished data and helpful discussions. We also thank Puzheng Zhang and Ashkan Salehzadeh for excellent technical assistance and all members of the transgenic facilities at Samuel Lunenfeld Research Institute and Sunnybrook Health Sciences Centre for production of chimeras. We are grateful to Mehrdad Hajibabaei, Kristina Nagy, and Maryam Faiz for critical reading of the manuscript. The SV2 antibody developed by Kathleen M. Buckley was obtained from the Developmental Studies Hybridoma Bank developed under the auspices of the NICHD and maintained by The University of lowa, Department of Biology.

Correspondence should be addressed to Dr. Andras Nagy, Samuel Lunenfeld Research Institute, 60 Murray Street, 5th floor, Room 5-1015, Toronto, ON M5T 3H7, Canada. E-mail: nagy@lunenfeld.ca.

DOI:10.1523/JNEUROSCI.4396-10.2011

Copyright $\odot 2011$ the authors $\quad 0270-6474 / 11 / 3111547-06 \$ 15.00 / 0$
}

In adults, nestin is expressed mainly in the subependymal zone and dentate gyrus of the brain where neural stem/progenitor cells reside (Reynolds and Weiss, 1992; Fukuda et al., 2003). In addition, nestin has been detected in the neuromuscular junction (NMJ) (Vaittinen et al., 1999; Kang et al., 2007) and renal podocytes (Chen et al., 2006).

IFs along with microtubules and actins are major components of the cytoskeleton. They have an established role in providing mechanical strength to various cells and tissues. Moreover, there is accumulating evidence that they participate in cellular organization and that they also are important determinants of key signaling pathways (Pallari and Eriksson, 2006; Eriksson et al., 2009). Recent in vitro studies have shown that nestin can protect neural progenitors against oxidant-induced cell death through interaction with Cdk5 (Sahlgren et al., 2006). Indeed, nestin can serve as a scaffold for Cdk5 and is able to regulate its kinase activity in vitro (Sahlgren et al., 2003, 2006).

Cdk5 is a serine/threonine kinase protein. The kinase activity of Cdk5 is regulated by binding to the highly specific regulatory subunits p35 and p39 (Tang et al., 1995; Dhavan and Tsai, 2001). In vivo expression of Cdk5 has been reported in proliferative as well as postmitotic neurons; however, Cdk5 kinase activity has only been detected in postmitotic neurons in which Cdk5 is bound to its activators (Chiasson et al., 1999). Mice deficient in Cdk5 expression die perinatally due to neural migration defects 
observed in the cerebral cortex, hippocampus, and cerebellum (Ohshima et al., 1996, 1999). Subsequent studies have revealed a novel role for $\mathrm{Cdk} 5$ at the NMJ. In contrast to agrin, a nerve-derived acetylcholine receptor (AChR)-stabilizing factor (Gautam et al., 1996), Cdk5 disperses AChR clusters (Delalle et al., 1997). Absence of Cdk5 can partially rescue the lack of stabilized AChR clusters in an agrin-null background (Delalle et al., 1997).

In the present study, we aim to decipher the role of nestin in vivo through generation of nestin knock-out mice via gene targeting. Our results indicate that although nestin-deficient mice are viable, the number of AChR clusters in their NMJ area is significantly increased. Moreover, through generation of nestin/agrin double knock-out mice, we show that, parallel to the case of Cdk5/agrin double knockouts, deficiency of nestin partially rescues dispersion of AChR clusters in an agrinnull background. These data suggest that nestin acts via the Cdk5 pathway in these developmental processes.

\section{Materials and Methods}

Construction of the targeting vector. To target the nestin locus, two homology arms were generated using standard recombineering technique (Liu et al., 2003). The following primers were used to generate the arms: 1-F: agagccgcggtcttgttggtcctcttcctca; 1-R: agagcctaggccatggcccetggaaaaggagttaca; 2-F: agagcctagggggtactggcacaggcatttaatc; 2-R: agaggcggccgccttaagattttccgaaagaggcttgagatac; 3-F: agagaagcttatgcatagagtcgcttagaggtgcagcag; 3-R: agagagatctccatggctaggaggtctcagaattccatcc; 4-F: agagagatctcatatggtggaggatggagaaggtca; 4-R: agaggtcgacctcgagttccagtccagctc.

A plasmid containing a PGK promoter, Neomycin resistance gene, and pA (PNT) (Tybulewicz et al., 1991) was cut with NotI and EcoRI. The pBSKII plasmid was also cut with NotI and EcoRI. The fragments were then ligated together. The 5' homology arm and the PNT-pBSKII product were then cut with NotI and SacII and ligated together. Finally, the $3^{\prime}$ homology arm and the $5^{\prime}$ armPNT-pBSKII vector were cut with HindIII and SalI, and the fragments were joined to generate the final targeting vector. The vector was linearized with SalI before electroporation.

Generation of the Nes ${ }^{+/-}$ES cells and $\mathrm{Nes}^{-/-}$mice. The linearized targeting vector was electroporated into G4 ES cells as previously described (George et al., 2007). The colonies were picked 8-12 d later and transferred to 96-well plates. The cells in 96-well plate were passaged. Subsequently one replica plate was frozen and the other used for DNA isolation for Southern blot analysis. A $5^{\prime}$ external probe was amplified using the following primers: F-acctagaggcctgagattctctaaa, R-caagatttttgatgaggaagaagaa. DNA was digested with SpeI and Southern blot was done according to a previously described protocol (George et al., 2007). The expected band size for wild-type and targeted allele was 20 and $14 \mathrm{~kb}$, respectively. Once targeted clones were identified, the corresponding clones were thawed and expanded for generation of chimeras via aggregation (Nagy et al., 1993). All the animal studies were performed in accordance with the institutional guidelines.

Western blot. Protein for Western blot was isolated from E10.5 embryos. Immediately after dissection, embryos were homogenized using a
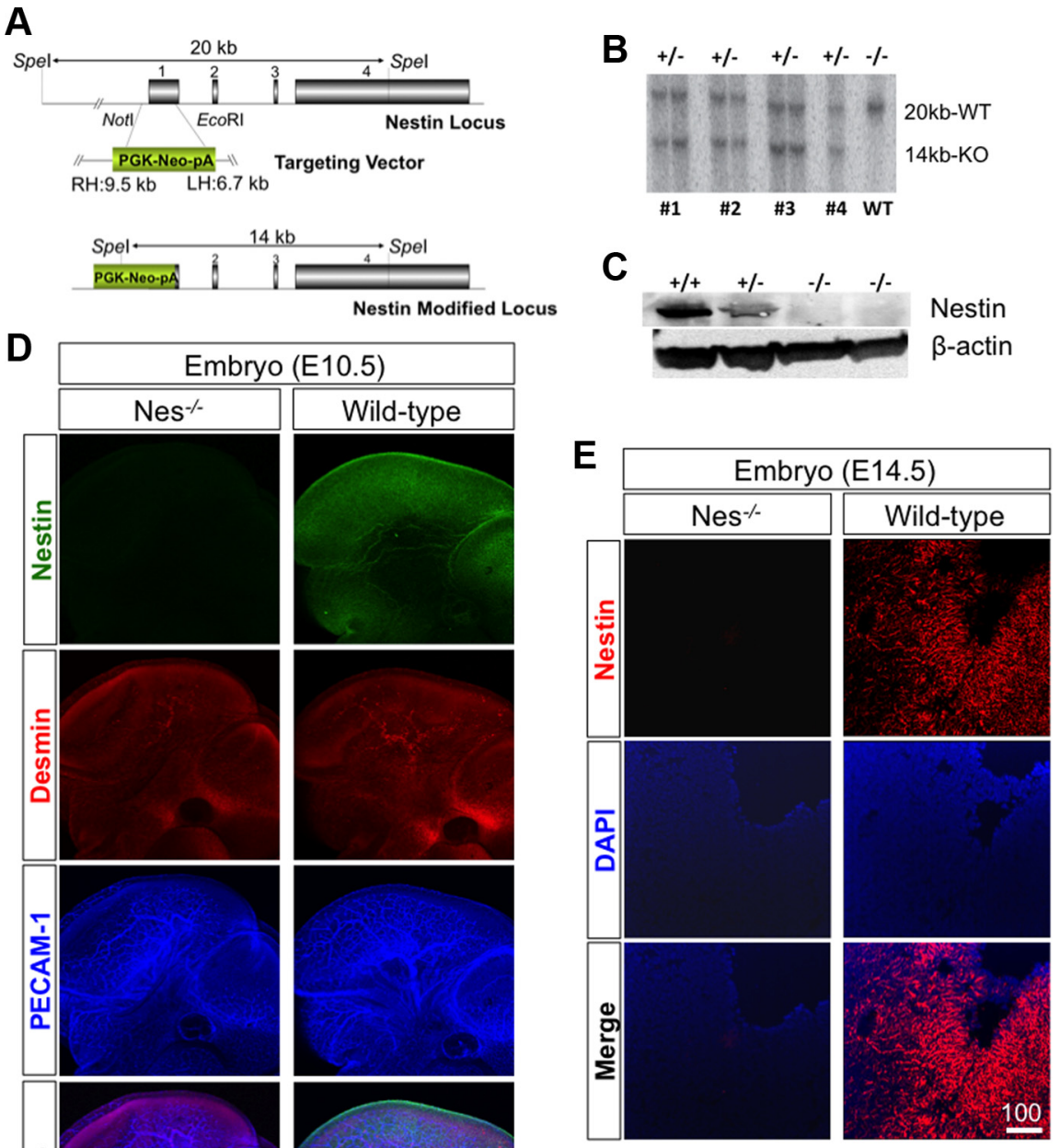

Figure 1. Generation of nestin-null mice. $\boldsymbol{A}$, Our target vector replaced most of exon 1 and part of the $5^{\prime}$ upstream region with a PGK promoter driven neomycin phosphotransferase (neo)-positive selectable marker. $\boldsymbol{B}$, Using a $5^{\prime}$ external probe, four targeted C, Western blot analysis. Nestin protein was absent in E10.5 homozygous embryos, while the appropriate amount was detected in heterozygous and wild-type embryos of the same litter. $\boldsymbol{D}, \boldsymbol{E}$, Immunohistochemical detection of nestin in E10.5 whole embryo (D) and cryosectioned brains of E14.5 embryos $(\boldsymbol{E})$. In all figures, scale bar sizes are in micrometers.

fine needle and protein was extracted as previously described (Sahlgren et al., 2006). Standard Western blot procedure was followed. The membrane was blocked in $2.5 \%$ milk diluted in TBS-T at $4^{\circ} \mathrm{C}$ overnight. The next day, the membrane was incubated for $1.5 \mathrm{~h}$ at room temperature in the following antibodies: (1) nestin (Millipore Bioscience Research Reagents) and (2) $\beta$-actin (Sigma).

Immunohistochemistry and image analysis. Whole-mounted tissues (diaphragm) were fixed with $4 \%$ paraformaldehyde, washed three times in PBS with $0.3 \%$ Triton X-100 (PBST), and incubated for $1 \mathrm{~h}$ at room temperature with blocking solution ( $5 \%$ goat serum). Samples were incubated overnight at $4^{\circ} \mathrm{C}$ with the following primary antibodies: (1) $\alpha$-bungarotoxin Alexa 594 conjugate (Invitrogen); (2) nestin (Millipore Bioscience Research Reagents); (3) desmin (Epitomics); (4) Neurofilament 150 (Millipore); (5) Neurofilament 200 (Sigma); (6) SV2 (Developmental Studies Hybridoma Bank); and (7) synaptophysin (Synaptic Systems). After several washes in PBST, tissues and sections were incubated for $2 \mathrm{~h}$ at room temperature with secondary antibodies: $\mathrm{Cy} 3$ or FITC or Cy5-conjugated secondary antibodies were used for signal detection (1:500 dilution, Jackson ImmunoResearch). For control experiments, the primary antibody was omitted or replaced by preimmune 

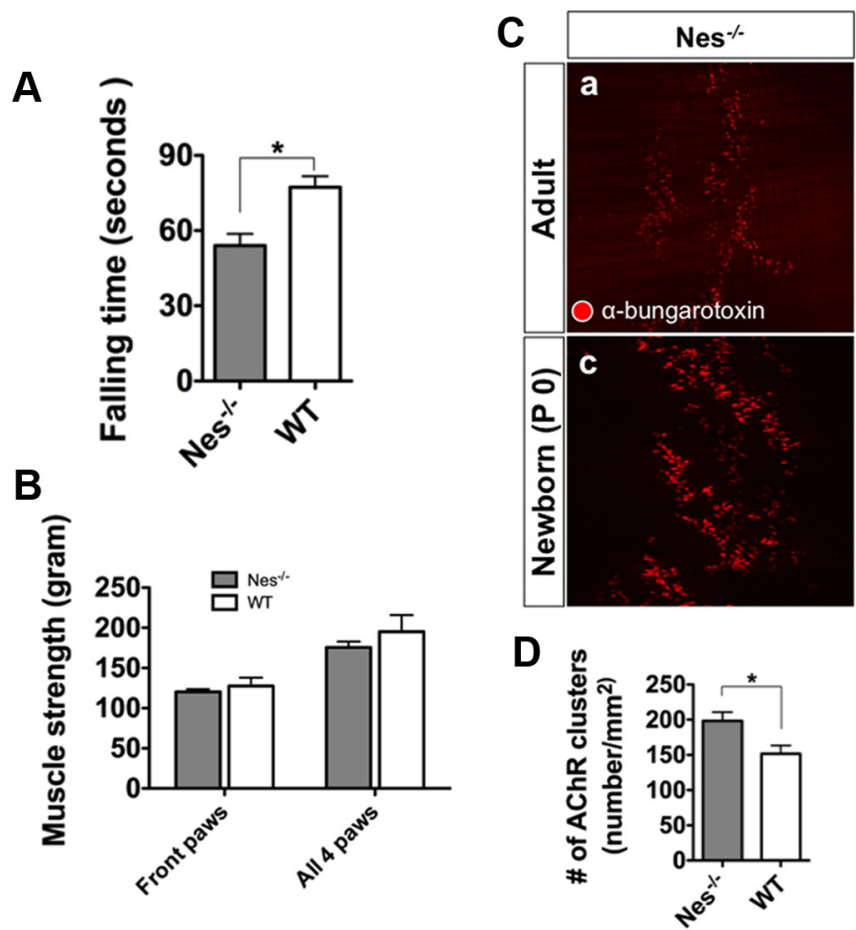

Figure 2. Phenotype of nestin-deficient mice. $\boldsymbol{A}$, Nestin-deficient mice showed reduced falling time compared to their wildtype littermates in the Roto-Rod test ( $n=5$ for WT and $n=11$ for Nes $^{-1-},{ }^{*} p<0.05$, Student's $t$ test). B, No significant difference was found in muscle strength of Nes ${ }^{-1-}$ mice compared with wild-type littermates ( $n=5$ for WT and $n=11$ for $\left.\mathrm{Nes}^{-1-}\right) . \mathrm{C}_{\text {, Nes }}{ }^{-1-}$ mice had more AChR clusters compared to wild types. AChR clusters in the Nes ${ }^{-1-}$ mice are dispersed in a larger muscle territory. Quantitation of this is shown in $\boldsymbol{D}\left(n=5\right.$ for WT and $n=5$ for Nes $\left.{ }^{-1-}\right)$ and $\boldsymbol{E}\left(n=6\right.$ for WT and $n=6$ for Nes ${ }^{-1-}, 3$ measurements taken for each sample; data are represented as mean $\pm \mathrm{SEM}^{*}{ }^{*} p<0.05$ and ${ }^{* *} p<0.01$, Student'sttest).

serum. To enhance the staining when using neurofilament and synaptic vesicle antibodies, the samples were fixed with $2 \%$ PFA and incubated in $0.1 \mathrm{M}$ glycine for $1 \mathrm{~h}$. Moreover the samples were incubated overnight at $4^{\circ} \mathrm{C}$ in primary antibodies. Signals were visualized and digital images were obtained using a Zeiss LSM 510 confocal microscope equipped with two-photon, argon and helium-neon lasers (Zeiss). Images were analyzed using ImageJ software to determine the area occupied by AChR clusters. The number of AChR clusters was determined by manual counting. Statistical significance was calculated by two-tailed paired Student's $t$ test. The number of samples used for characterization of AChR clusters in single knock-outs was 5 for each group $\left(\mathrm{Nes}^{-1-}\right.$ and their WT littermates). The number of samples used for characterization of AChR clusters in double knock-outs was 3 for each group $\left(\mathrm{Nes}^{-1-} ; \mathrm{Agrn}^{-1-}\right.$ and their $\mathrm{Nes}^{+/+} ; \mathrm{Agrn}^{-/-}$littermates). The number of samples used for endplate bandwidth calculations were as follows: $n=6$ for WT and $n=$ 6 for $\mathrm{KO}$ used for bandwidth calculation of $\mathrm{Nes}^{-1-}$ and their WT littermates, $n=3$ for WT and $n=3$ for KO used for nerve length calculation of $\mathrm{Nes}^{-1-}$ and their WT littermates with neurofilament staining, $n=4$ for WT-anterior and $n=5$ for WT-posterior sections.

Neurobehavioral tests. Roto-Rod test was used to examine the ability of mice to maintain their balance and coordinate their movement. Mice were tested using previously described methods (Kuhn et al., 1995). Briefly, mice were placed on top of the beam facing away from the experimenter's view (four mice tested at a time). After a brief training period, the Roto-Rod starts accelerating gradually and latencies for the mice to fall from the rod were recorded. Each mouse was tested three times per day for 3 consecutive days (same time and location every day). To examine muscles, a grip strength test was used. The mouse was lifted by the tail and allowed to grasp the steel grip. Then it was gently pulled backward until the grip was released. The machine records the force before the release. Each mouse was tested three times. To test the balance, mice were trained to walk on a long beam. The following day, mice were put on the same beam and the time needed to walk from start to end point was recorded. The numbers of animals used for neurobehavioral tests were as
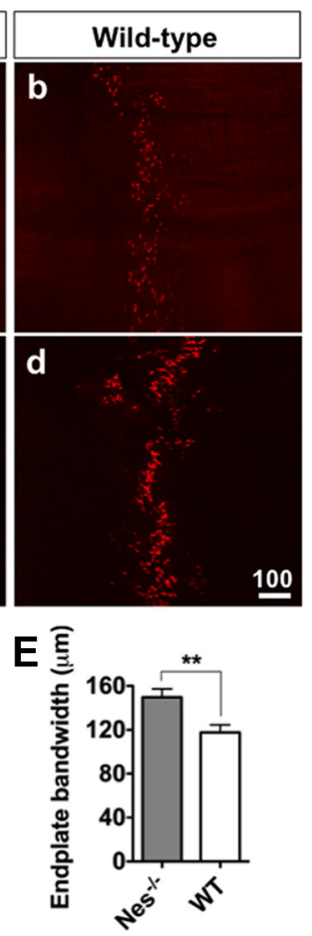

follows: $n=5$ for WT ( 4 males and 1 female), $n=11$ for $\mathrm{KO}$ ( 5 males and 6 females). The sex of the mice did not have a significant effect on the results.

\section{Results}

Generation of nestin-deficient mice

The mouse nestin gene (Nes) comprises four exons spread over a $12 \mathrm{~kb}$ genomic region on chromosome 3 . To generate a null mutation, we replaced almost the entire first exon and part of the $5^{\prime}$ upstream region with a PGK promoter driving neomycin phosphotransferase (neo) using homologous recombination-based targeting (Fig. 1A). Of 239 neo-resistant colonies screened, four targeted clones were identified by Southern blot analysis (Fig. $1 B$ ). All four clones were used to generate chimeric founder mice from the ES cells by tetraploid embryo complementation (Nagy et al., 1993). Two lines successfully resulted in completely ES cell-derived males and transmitted the mutant allele to their offspring. These two lines were used for subsequent studies. We analyzed the nestin mutation in two different genetic backgrounds; the G4 (George et al., 2007) ES cell-derived founders [C57BL/6 (B6), 129/Sv F1 hybrid] were crossed either to ICR (outbred) or B6. The latter were backcrossed three times to B6 to minimize 129 contributions. We have not observed any variation caused by the genetic background or between the two independent gene-targeted lines.

Western blot analysis did not detect nestin protein in $\mathrm{Nes}^{-1-}$ embryos (E10.5) obtained by crossing heterozygous parents, while the protein was observed in both $\mathrm{Nes}^{+/-}$and $\mathrm{Nes}^{+/+}$embryos (Fig. 1C), proving the null mutation nature of our targeted allele. Nestin expression was further examined at the cellular level by immunohistochemistry of both whole-mount embryos (E10.5) (Fig. 1D) and cryosectioned tissues (E14.5) (Fig. 1E). While strong nestin signal was detected in $\mathrm{Nes}^{+/+}$mice, the signals in $\mathrm{Nes}^{-1-}$ mice were the same as the background level, further supporting the absence of nestin in the homozygous mutants (Fig. 1E). Since nestin has a short N-terminal domain it is not able to form a filamentous network on its own and is often copolymerized with vimentin, a class III intermediate filament protein (Marvin et al., 1998). Therefore, we examined the expression level of this intermediate filament in nestin knock-out embryos. We did not observe a significant difference in vimentin protein level in nestin knock-out embryos compared with their wild-type littermates (supplemental Fig. 1, available at www.jneurosci.org as supplemental material). These observations suggest that absence of nestin is not compensated by upregulation of vimentin.

\section{Nestin is dispensable for mouse development}

Since nestin is expressed as early as E7.5 in the neuroepithelium and between E9 and E11 in the heart (Kachinsky et al., 1995), we examined the developing CNS and cardiovascular system of $\mathrm{Nes}^{-1-}$ embryos at E10.25 along with their wild-type littermates as controls. Both systems were anatomically normal (supplemental Fig. 2, available at www.jneurosci.org as supplemental 
material). The interbreed of $\mathrm{Nes}^{+/-}$ heterozygous parents yielded the expected Mendelian ratios of $\mathrm{Nes}^{+/+}, \mathrm{Nes}^{+/-}$, and $\mathrm{Nes}^{-1-}$ mice, indicating that nestin deficiency does not cause embryonic lethality (supplemental Table 1, available at www. jneurosci.org as supplemental material). All genotypes reached sexual maturity and were fertile. We did not observe any differences in size or body weight between the groups (data not shown). Histological examination of various tissues (e.g., CNS, muscle, and kidney) did not reveal any apparent morphological abnormalities resulting from the absence of nestin expression in the examined mice (supplemental Fig. 3, available at www.jneurosci. org as supplemental material). However, these investigations could not rule out the possibility of subtle changes arising from the absence of nestin. Because nestin is highly expressed in progenitors of the CNS, we decided to further examine the brain structure by magnetic resonance imaging. No significant difference was detected when different regions of the brain were compared between nestin-deficient and wild-type mice (supplemental Fig. $4 A, B$, available at www.jneurosci.org as supplemental material). As an overall conclusion, our data suggest that nestin deficiency does not have a negative effect on mouse development and tissue structure at a gross anatomical level.

\section{Nestin is required for proper peripheral motor function}

To further characterize nestin-deficient mice, we performed a series of peripheral type neurobehavioral functional tests such as motor coordination and balance test. The Roto-Rod test (Kuhn et al., 1995) was used to assay coordination and function of motor neurons. Mice were placed on a controlled rotating rod and their latency to fall was measured. $\mathrm{Nes}^{-1-}$ mice showed a lower average latency compared with their wild-type littermates (Fig. $2 \mathrm{~A}$ ). Since lower than expected performance in a Roto-Rod test could be caused by lower grip strength, we proceeded to directly examine muscle strength in nestin-deficient mice. We did not detect any significant differences in grip strength of either forelimbs or hindlimbs between knock-out and control groups (Fig. 2 B). Performance in the Roto-Rod test can also be influenced by the ability to maintain balance. Consequently, we tested both experimental and control groups in a long rod balance test but did not observe any significant differences between the groups (data not shown). The above experiments excluded two factors, muscle strength and balance, which could have caused the poor performance of nestin-deficient mice on the Roto-Rod system. Therefore, we postulated that the poor performance was related to abnormalities in connection of peripheral nervous system to muscles, namely the NMJ (Hirsch, 2007).

Increased number of $\mathrm{AChR}$ clusters and broadened cluster bandwidth in NMJ of $\mathrm{Nes}^{-/-}$mice

Both nestin and Cdk5 are expressed at the NMJ (Vaittinen et al., 1999; Fu et al., 2001; Kang et al., 2007), and the latter has recently been shown to play a major role in dispersion of AChR clusters during NMJ development (Delalle et al., 1997; Fu et al., 2005). In vitro studies have also shown that nestin serves as a scaffold for Cdk5 and through this interaction can regulate Cdk5/p35 signaling (Sahlgren et al., 2006). Therefore, we examined the NMJs and the pattern of AChR clusters in nestin-deficient mice. We focused on the diaphragm muscle, where AChR cluster formation and maintenance has been well studied by visualization of $\alpha$-bungarotoxin $(\alpha-B T X)$ binding. Interestingly, we found that nestin mutants have more AChR clusters compared with their wild-type littermates. Furthermore, AChR clusters occupy a larger muscle territory in nestin mutants (Fig. $2 \mathrm{Ca}, \mathrm{Cb}$ ). To assess whether the observed phenotype is a congenital defect, we analyzed AChR clusters of newborn mice (P0). Similar to the adult mice, the number and area of AChR clusters were increased in nestin-deficient newborns, indicating that the observed phenotype is indeed a developmental defect (Fig. $2 C c, C d, D, E$ ). It is important to note that the endplate bandwidth varies at different sites of the diaphragm (supplemental Fig. 5, available at www. jneurosci.org as supplemental material). Therefore, in our analysis, we always matched and compared the same area of the nestin knock-out diaphragm with that of the wild-type.

Next we analyzed the nerve and synapse component of the $\mathrm{NMJ}$ in relation to the AChR clusters. We covisualized the clusters, the nerves, and the synaptic vesicles by $\alpha-B T X$, neurofilament, and the mixture of synaptophysin and synaptic vesicle protein 2 (SV2) antibodies, respectively (Fig. $3 A, B$ ). We observed that although the endplate bandwidth is broadened in 

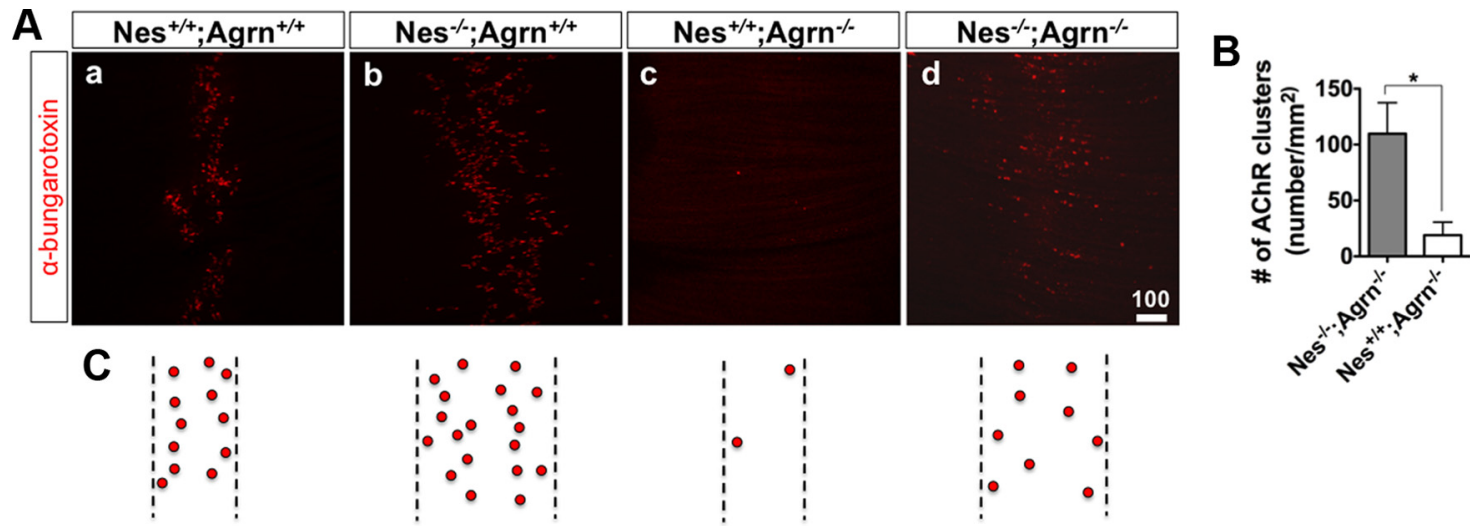

- Acetylcholine receptor cluster

Figure 4. Nestin deficiency can rescue maintenance defect of AChR clusters in agrin-null background. $\boldsymbol{A}$, Immunofluorescent staining using $\alpha$-bungarotoxin showed increased AChR clusters in

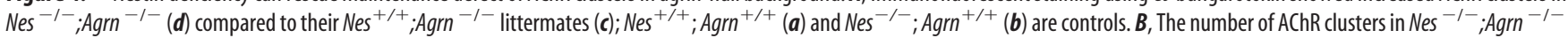
mice was higher than that of their Nes ${ }^{+/+} ; A g r n^{-/-}$littermates. ( $n=3$ for each group, data are represented as mean $\pm S E M$, ${ }^{*} p<0.05$, Student's $t$ test). $\boldsymbol{C}$, Schematic illustration of AChR clusters in all analyzed genotypes.

nestin-deficient embryos, AChR clusters were innervated in both wild-type and nestin mutant samples. In agreement with this finding, the nerve length was significantly increased in the knockout samples compared with the wild-type controls (Fig. 3C).

\section{Nestin regulates activity of Cdk5 in vivo: evidence from nestin/agrin double knock-out mice}

Previous studies on agrin-deficient mice have shown that AChR clusters are initially made in these mutants but are dispersed at later stages, suggesting that the motor neuron-derived agrin works against a dispersion signal to maintain AChR clusters in NMJs (Gautam et al., 1996). Follow-up studies have identified Cdk5 as the dispersing agent responsible for disassembling the AChR clusters. Moreover, a significant number of AChR clusters are maintained in agrin/Cdk5 double knock-outs, whereas they would have been dispersed in the presence of Cdk5 activity in agrin single knock-outs (Delalle et al., 1997). These observations indicate that the opposing roles of agrin and Cdk5 as positive and negative signals, respectively, shape and maintain the AChR clusters in NMJ. Thus, as nestin is suggested to be a modulator of Cdk5 kinase activity (Sahlgren et al., 2006), increased number of AChR clusters observed in the nestin-deficient mice could reflect reduced effects of Cdk5. To investigate this hypothesis, we used a genetic approach. We generated nestin/agrin double knock-outs and examined clustering of AChRs at E17.5-E18.5 of development. Remarkably, we observed many AChR clusters in nestin/ agrin double knock-out mutants, whereas the number of clusters was significantly less in agrin single knock-outs (Fig. $4 A-C)$. This observation indicates that lack of nestin in the agrin-null background leads to partial maintenance of AChR clusters and substantiates the role of nestin in Cdk5 pathway for NMJ development.

\section{Discussion}

Here we report the generation of nestin knock-out mice via gene targeting. The characterization of nestin-deficient mice revealed the essential role of nestin in the development of NMJs. Nestin knock-out mice have more AChR clusters and broadened cluster bandwidth. Similar to our nestin deficiency phenotype, the number of AChR clusters in Cdk5-deficient embryos is significantly higher than in wild-type controls (Delalle et al., 1997; Fu et al., 2005). This is in line with the expectation from in vitro studies showing that nestin serves as a scaffold for Cdk 5 and regulates its kinase activity (Sahlgren et al., 2006). A recent RNAi-based study (Yang et al., 2011) further supports our conclusion as knockdown of nestin via RNAi in myotubes resulted in significant decrease of p35 expression and Cdk5 activity. Further support for the notion that nestin acts via the Cdk5 pathway was obtained from the similarity between the phenotypes of Cdk5/agrin and nestin/agrin double knock-out animals. In all cases [i.e., Cdk5 deficiency (Lin et al., 2005), nestin RNAi knockdown (Yang et al., 2011), and nestin deficiency (our study)], the AChR clusterdispersing phenotype was partially rescued in agrin mutants. Our genetic and others' biochemical data (Sahlgren et al., 2006; Yang et al., 2011) strongly suggest that nestin is an important regulator of Cdk5 kinase activity identified as a dispersing signal for AChR clusters.

In summary, our data indicate that although nestin is highly expressed during CNS development and commonly used for detection of neural stem/progenitor cells, it is dispensable for formation of the CNS. Nestin deficiency leads to increased nerve length, endplate bandwidth, and number of AChR clusters in the NMJ. Furthermore, our data from nestin/agrin double mutants signify the importance of nestin as a regulator of Cdk5 kinase activity leading to modulation of certain cell signaling events in vivo and suggest a novel role for nestin in Cdk5-mediated maintenance/dispersion of AChR clusters.

\section{References}

Chen J, Boyle S, Zhao M, Su W, Takahashi K, Davis L, Decaestecker M, Takahashi T, Breyer MD, Hao CM (2006) Differential expression of the intermediate filament protein nestin during renal development and its localization in adult podocytes. J Am Soc Nephrol 17:1283-1291.

Chiasson BJ, Tropepe V, Morshead CM, van der Kooy D (1999) Adult mammalian forebrain ependymal and subependymal cells demonstrate proliferative potential, but only subependymal cells have neural stem cell characteristics. J Neurosci 19:4462-4471.

Delalle I, Bhide PG, Caviness VS Jr, Tsai LH (1997) Temporal and spatial patterns of expression of p35, a regulatory subunit of cyclin-dependent kinase 5, in the nervous system of the mouse. J Neurocytol 26:283-296.

Dhavan R, Tsai LH (2001) A decade of CDK5. Nat Rev Mol Cell Biol 2:749-759.

Doetsch F, García-Verdugo JM, Alvarez-Buylla A (1997) Cellular composition and three-dimensional organization of the subventricular germinal zone in the adult mammalian brain. J Neurosci 17:5046-5061.

Eriksson JE, Dechat T, Grin B, Helfand B, Mendez M, Pallari HM, Goldman 
RD (2009) Introducing intermediate filaments: from discovery to disease. J Clin Invest 119:1763-1771.

Fröjdman K, Pelliniemi LJ, Lendahl U, Virtanen I, Eriksson JE (1997) The intermediate filament protein nestin occurs transiently in differentiating testis of rat and mouse. Differentiation 61:243-249.

Fu AK, Fu WY, Cheung J, Tsim KW, Ip FC, Wang JH, Ip NY (2001) Cdk5 is involved in neuregulin-induced AChR expression at the neuromuscular junction. Nat Neurosci 4:374-381.

Fu AK, Ip FC, Fu WY, Cheung J, Wang JH, Yung WH, Ip NY (2005) Aberrant motor axon projection, acetylcholine receptor clustering, and neurotransmission in cyclin-dependent kinase 5 null mice. Proc Natl Acad Sci U S A 102:15224-15229.

Fukuda S, Kato F, Tozuka Y, Yamaguchi M, Miyamoto Y, Hisatsune T (2003) Two distinct subpopulations of nestin-positive cells in adult mouse dentate gyrus. J Neurosci 23:9357-9366.

Gautam M, Noakes PG, Moscoso L, Rupp F, Scheller RH, Merlie JP, Sanes JR (1996) Defective neuromuscular synaptogenesis in agrin-deficient mutant mice. Cell 85:525-535.

George SH, Gertsenstein M, Vintersten K, Korets-Smith E, Murphy J, Stevens ME, Haigh JJ, Nagy A (2007) Developmental and adult phenotyping directly from mutant embryonic stem cells. Proc Natl Acad Sci U S A 104:4455-4460.

Hirsch NP (2007) Neuromuscular junction in health and disease. Br J Anaesth 99:132-138.

Kachinsky AM, Dominov JA, Miller JB (1995) Intermediate filaments in cardiac myogenesis: nestin in the developing mouse heart. J Histochem Cytochem 43:843-847.

Kang H, Tian L, Son YJ, Zuo Y, Procaccino D, Love F, Hayworth C, Trachtenberg J, Mikesh M, Sutton L, Ponomareva O, Mignone J, Enikolopov G, Rimer M, Thompson W (2007) Regulation of the intermediate filament protein nestin at rodent neuromuscular junctions by innervation and activity. J Neurosci 27:5948-5957.

Kaplan MP, Chin SS, Fliegner KH, Liem RK (1990) Alpha-internexin, a novel neuronal intermediate filament protein, precedes the low molecular weight neurofilament protein (NF-L) in the developing rat brain. J Neurosci 10:2735-2748.

Kuhn PL, Petroulakis E, Zazanis GA, McKinnon RD (1995) Motor function analysis of myelin mutant mice using a rotarod. Int J Dev Neurosci 13:715-722.

Lendahl U, Zimmerman LB, McKay RD (1990) CNS stem cells express a new class of intermediate filament protein. Cell 60:585-595.

Lin W, Dominguez B, Yang J, Aryal P, Brandon EP, Gage FH, Lee KF (2005) Neurotransmitter acetylcholine negatively regulates neuromuscular synapse formation by a Cdk5-dependent mechanism. Neuron 46:569-579.

Liu P, Jenkins NA, Copeland NG (2003) A highly efficient recombineering- based method for generating conditional knockout mutations. Genome Res 13:476-484.

Marvin MJ, Dahlstrand J, Lendahl U, McKay RD (1998) A rod end deletion in the intermediate filament protein nestin alters its subcellular localization in neuroepithelial cells of transgenic mice. J Cell Sci 111:1951-1961.

Mignone JL, Kukekov V, Chiang AS, Steindler D, Enikolopov G (2004) Neural stem and progenitor cells in nestin-GFP transgenic mice. J Comp Neurol 469:311-324.

Nagy A, Rossant J, Nagy R, Abramow-Newerly W, Roder JC (1993) Derivation of completely cell culture-derived mice from early-passage embryonic stem cells. Proc Natl Acad Sci U S A 90:8424-8428.

Ohshima T, Ward JM, Huh CG, Longenecker G, Veeranna, Pant HC, Brady RO, Martin LJ, Kulkarni AB (1996) Targeted disruption of the cyclindependent kinase 5 gene results in abnormal corticogenesis, neuronal pathology and perinatal death. Proc Natl Acad Sci U S A 93:11173-11178.

Ohshima T, Gilmore EC, Longenecker G, Jacobowitz DM, Brady RO, Herrup K, Kulkarni AB (1999) Migration defects of cdk5(-/-) neurons in the developing cerebellum is cell autonomous. J Neurosci 19:6017-6026.

Pallari HM, Eriksson JE (2006) Intermediate filaments as signaling platforms. Sci STKE 2006:pe53.

Reynolds BA, Weiss S (1992) Generation of neurons and astrocytes from isolated cells of the adult mammalian central nervous system. Science 255:1707-1710.

Sahlgren CM, Mikhailov A, Vaittinen S, Pallari HM, Kalimo H, Pant HC, Eriksson JE (2003) Cdk5 regulates the organization of Nestin and its association with p35. Mol Cell Biol 23:5090-5106.

Sahlgren CM, Pallari HM, He T, Chou YH, Goldman RD, Eriksson JE (2006) A nestin scaffold links Cdk5/p35 signaling to oxidant-induced cell death. EMBO J 25:4808-4819.

Sejersen T, Lendahl U (1993) Transient expression of the intermediate filament nestin during skeletal muscle development. J Cell Sci 106:1291-1300.

Tang D, Yeung J, Lee KY, Matsushita M, Matsui H, Tomizawa K, Hatase O, Wang JH (1995) An isoform of the neuronal cyclin-dependent kinase 5 (Cdk5) activator. J Biol Chem 270:26897-26903.

Tybulewicz VL, Crawford CE, Jackson PK, Bronson RT, Mulligan RC (1991) Neonatal lethality and lymphopenia in mice with a homozygous disruption of the c-abl proto-oncogene. Cell 65:1153-1163.

Vaittinen S, Lukka R, Sahlgren C, Rantanen J, Hurme T, Lendahl U, Eriksson JE, Kalimo H (1999) Specific and innervation-regulated expression of the intermediate filament protein nestin at neuromuscular and myotendinous junctions in skeletal muscle. Am J Pathol 154:591-600.

Yang J, Dominguez B, de Winter F, Gould TW, Eriksson JE, Lee KF (2011) Nestin negatively regulates postsynaptic differentiation of the neuromuscular synapse. Nat Neurosci 14:324-330. 